Woods Hole Oceanographic Institution

Towed Digital Camera and Multi-Rock Coring System

\title{
Technical and Operations Manual
}

\author{
Daniel J. Fornari \\ Woods Hole Oceanographic Institution \\ Geology \& Geophysics Dept. \\ Woods Hole, Massachusetts 02543 \\ Tel: 508-289-2857 \\ Fax: 508-457-2187 \\ email: dfornari@whoi.edu
}

\section{Version 1.0}

August 1, 2002 
Acknowlegements

\section{Contents}

Specifications

Introduction

Mechanical Design

Electronic Design

Power

Imaging Data Capacity

Data Handling

Operations Guidelines

Towed Camera System Battery Charging Protocol

Battery Charging Information

Preparing for a Camera Tow

Launching the TowCam

Towing the Tow Cam

Recovering the TowCam

Pre- and Post Launch - Benthos 5010 Data Set up and Downloading

Crib Sheet for Downloading Digital Images

Steps for Digital Camera Set Up Before a Tow

Steps for Downloading Images After a Tow

Filling and Checking Compensating Oil in Battery Boxes

Plate and Figure Captions

\section{Acknowledgements}

Observations of the ocean floor are critical to understanding the processes taking place there. Bruce Heezen first introduced me to the nuances and beauty of seafloor photography and its value to scientific investigations. In graduate school and after I was mentored by Bill Ryan who developed innovative approaches to deep sea photography and stimulated my interest in pursuing this type of data acquisition to complement other marine geological studies. When I arrived at WHOI in 1993, I collaborated with Earl Young who helped me construct a simple deep sea camera system. His tenacity at finding components of the old ANGUS system and skill at making them work is a testament to traditional oceanography.

The current Towed Digital Camera and Multi-Rock Coring System (TowCam) benefits from experience with the original Benthos 5010 digital deep sea camera that was used on the WHOI towed camera system from 1996 to 2001. Bill Hersey of Benthos made a substantive contribution to this system in developing the digital camera used on the old sled and in assisting with upgrades. Greg Kurras assisted in the operation of the camera on many tows as part of his Master thesis at the Univ. of Hawaii. When the old towed camera was lost on the Northwest rift zone of Fernandina Volcano, in the western Galápagos in September 2001, an opportunity to upgrade and refine the system presented itself. Using a combination of funds from the National Science Foundation (Grant\#OCE-0097084) and insurance money from the lost camera, the current system was designed and built with the help of many people.

All of the following individuals assisted in this project. Their dedication, expertise and patience is greatly appreciated and acknowledged. From WHOI - Andy Billings, Rod Catanach, Al Duester, Al Bradley, Steve Liberatore, Marshall Swartz, Terry Hammar, Ken 
Doherty, George Meier, Paul Fucile, Barrie Walden, Rick Chandler, Kate Buckman and Maryanne Ferreira. From DeepSea Power \& Light - Mark Olsson, Jeff Prsha, John Chew, Bill Easley, Pete Kwei, and Mike Steinnel. From U. Hawaii, Hawaii Mapping Research GroupPaul Johnson. From Southhampton Oceanography Centre- Rhian Waller. 
$2 / 26 / 03$

\section{WHOI Towed Digital Camera and Multi-Rock Coring System}

\section{System Summary:}

The WHOI TowCam is a self-recording, deep-sea towed camera system rated to 6000 meters. It is capable of remotely taking $\sim 1000$ high-resolution color digital photographs at intervals of 10-60 seconds, of various seafloor terrains while being towed $\sim 5-7 \mathrm{~m}$ above the bottom at speeds of $\sim 1 / 4-1 / 3$ knot using a UNOLS standard, coaxial CTD cable. The onboard CTD (SeaBird25) permits real-time display and recording of digital depth, altitude and other standard CTD sensors (e.g. conductivity, temperature, turbidity), and provides connectivity to the pylon that permits triggering of the rock corers.. A strobe monitor ("Flashbird"), connected to a spare serial port in the SBE25, indicates when the strobes are fired. This is displayed on the laptop computer in the ship's lab and provides real-time verification that the camera is functioning and strobes are firing. The system is also equipped with six (6) specially designed rock core winches that permit the user to take discrete samples of volcanic glass by triggering the CTD deck unit and pylon, in much the same way as a CTD Niskin bottle is triggered on a rosette system. It is envisioned that sampling sites would be predetermined based on inferred geological contacts displayed in high-resolution sonar imagery or bathymetry. When a corer is triggered via the SBE33 Deck Unit and plyon, controlled from the CTD laptop, the corer winch starts turning, and in so doing, the $\sim 8 \#$ wax-coated stainless steel core head is released and free-falls to the seafloor on a $\sim 10$ meter, $200 \#$ test, monofilament tether. The core head bounces on the lava flow and is dragged over it as the Tow Cam continues its traverse, thereby breaking off chips of glass and embedding them in the wax. Each corer winch is designed to reel-up the $\sim 10 \mathrm{~m}$ length of tether in approximately 4 minutes, however, the amount of time that the core head is actually in contact with the seafloor varies depending on the altitude when deployed. Nominally, at $\sim 5 \mathrm{~m}$ altitude, the core head is in contact with the seafloor for about 1-1.5 minutes. At a speed of $\sim 1 / 4$ knot, this equates to a horizontal distance traveled of approximately $10 \mathrm{~m}$. When the core head is fully retrieved (a current limiter prevents the winch motor from over-pulling), it is stowed inside a 4" plexiglass tube and a gear stop prevents the core head from redeploying. The time of each corer deployment is recorded by the CTD system.

The WHOI TowCam is intended to be able to be operated by technicians and/or scientists having familiarity with the basic system components and experience in towing nearbottom imaging systems. Costs for operation of the camera have been tentatively set at $\$ 1000$. per tow. This fee includes all expendables, a per-tow maintenance cost, and archiving of acquired images on CDs for the science party. In addition to the per tow costs, users should budget for shipping of the system to and from the research vessel to Woods Hole, MA and over-the-side insurance to cover the $\sim \$ 196,000$. replacement cost of the system. System operational costs, insurance and shipping logistics can be provided through WHOI as a subcontract. Interested users should contact Dan Fornari (dfornari@whoi.edu) for details regarding the system, scheduling, availability of seagoing technicians, if required, and cost estimates. 
WHOI Tow Cam Specifications:

Maximum deployment depth

$6000 \mathrm{~m}$

Weight in air

1300 pounds

Weight in water

850 pounds

Normal tow speed (for best imaging and photo overlap)

-1/4-1/3 knot

Maximum tow speed

Digital image recording capacity

Digital image size/format

Digital imaging camera

Digital imaging storage

Photo repetition rate

Deep sea strobe

Strobe recharge time (minimum)

Power (Camera, Strobes, Coring Winches)

24VDC DSPL SeaBattery Re-Charge time

CTD System

Flashbird (Strobe Monitor)

Rock Coring Winches

\section{1/2 knot (in flat terrain only)}

1000 digital, color still images

$\sim 800 \mathrm{~kb}$ to $1 \mathrm{MB}$ files in .jpg format

DSPL DigiSeaCam

(Nikon 995 camera in DSPL Aluminum

housing with water corrected optics)

1 Gigabyte CompactFlash card

$10 \mathrm{sec}$ to $60 \mathrm{sec}$

Benthos Model 383 electronics with two $300 \mathrm{watt} / \mathrm{sec}$ Benthos 386 flash-heads

$\sim 8 \mathrm{sec}$.

Four (4) 24VDC $42 \mathrm{amp} / \mathrm{hr}$ DSPL SeaBatteries Batteries \#1\&2 - Strobe Battery \#3 - Camera Battery \#4 - Corer Winches

$\sim 2-4$ hrs.

SeaBird25, including altimeter, depth, conductivity, temperature, and turbidity sensor, and

SBE33 Deck Unit for triggering corer winches

via $0.322 "$ coaxial UNOLS sea cable

WHOI built- uses CTD serial port

WHOI designed and built (current capacity is 6 winches per lowering) each corer head weighs $\sim 81$ bs in water 
$2 / 26 / 03$

\section{Overview and Introduction}

The new WHOI Towed Digital Camera and Multi-Rock Coring System (TowCam) is an internally recording digital deep sea camera system that also permits acquisition of volcanic glass samples using up to six (6) rock cores in conjunction with CTD water properties data. The TowCam is towed on a standard UNOLS coaxial CTD sea cable, thereby permitting realtime acquisition of digital depth and altitude data that can be used to help quantify objects in the digital images. The use of the conducting sea cable and CTD system also permits triggering of any of six rock core units on the sled so that discrete samples of volcanic glass can be collected during a lowering from specific areas identified using sonar data. By operating either at night in between Alvin dives, or during other seagoing programs, photographic information of the seafloor can be recorded for near real-time analysis and for planning subsequent Alvin dives or other sampling/surveying programs.

The TowCam height off-bottom is monitored in real-time using primarily the altimeter on the CTD along with a backup $12 \mathrm{kHz}$ pinger. The TowCam altitude is controlled by hauling in and paying out the CTD wire at the lab winch control station. Because the camera is towed only 5-7 $\mathrm{m}$ above the seafloor great care must be taken to avoid hitting the bottom. Detailed multibeam bathymetry maps are a prerequisite for operation of the system. In general camera tows should be conducted along or oblique to bathymetry contours for best towing and safety. Camera and strobes functionality is verified during a tow using the "Flashbird"; a light sensor developed by Mr. Paul Fucile at WHOI that plugs into one of the available serial ports on the Seabird25 CTD.

A Tow Cam technician, or dedicated person in the science party, should be responsible for preparing the system for subsequent tows and for maintenance. Operating the TowCam requires experienced personnel. Training and supervision of science users in safe and successful towing of the TowCam_by a qualified technician is required. The ship's bosun is critical to the safe launch and recovery of the TowCam_and every effort should be made to follow the bosun's instructions and to go over deployment/recovery plans. Detailed discussions with the ship's officers in regards to tow start and end points, water depths and topography is also very important. A detailed log is required for each lowering of the TowCam. Those logs, along with maintenance records and charging data sheets are to be returned to WHOI with the system after use.

\section{Mechanical Design}

The TowCam frame is made of stainless steel with a bridle and lift point suitable for connection to standard UNOLS CTD terminations. The frame is constructed to withstand moderate abuse in order to protect the camera components from contact with the ocean bottom or other objects such as the ship and shipboard equipment. The design and large sail area of the 'tail' provide towing stability to the sled in a nose forward attitude under normal conditions.

It is important to ensure that all sled components are firmly attached to the sled. For the electronics pressure cases this means ensuring that all bolts have lock nuts or lock washers. For the battery boxes the straps and strap hardware must be in good shape. Replace any straps that have corroded mechanisms or frayed strapping. All cables have to be tied and taped securely to the sled. Plastic wire-ties have been used throughout to ensure that no cable or cable bundle is loose and that they are not pulling tightly on connections which could make them come loose or unplug during the tow.

The oil used to compensate the gel-cell batteries for pressure in the DSPL SeaBatteries is carnation oil (vegetable oil). The junction boxes and winch motors are compensated with DC20 oil. A supply of each type of oil is provided in the spares for the TowCam. 


\section{Electrical Design}

The electronic design of the system was developed to take advantage of the capabilities and requirements of the four major components of the TowCam: the Seabird25 CTD, the DSPL DigiSeacam digital camera, the Benthos 383 strobe and flash-heads, and the WHOI corer winches. The SeaBird25 CTD is powered through the 0.322" coaxial sea cable and data are transmitted through the sea cable to the ship for real-time monitoring of depth, altitude, flash confirmation (via the 'Flashbird') and water properties. The sea cable also powers the modified pylon (Command Release Module - [CRM]) used to trigger the core winches. The other system components (camera, winches and strobe) operate using the DSPL SeaBatteries each having a rating of $24 \mathrm{VDC} 42 \mathrm{amp} / \mathrm{hr}$. Two batteries are combined in parallel to provide power for the strobes. One battery supplies power to the digital camera and the other battery supplies power to the rock core winches.

The WHOI designed power distribution system (Steve Liberatore) and corer winches (Ken Doherty and Terry Hammar) were designed to interface with the SeaBird pylon that normally is used to trigger Niskin bottles. SeaBird modified their normal 24 position plyon per specifications delivered to them by Steve Liberatore and Marshall Swartz (when used with the TowCam this unit has been named the Command Release Module - [CRM]). The power distribution and control electronics designed and built by Liberatore consist of pressure tolerant components housed in two small junction boxes that are mounted on the TowCam frame. Detailed documentation and drawings of the electrical design and J-box wiring are provided separately.

\section{Power}

The four, 24 VDC DSPL SeaBatteries each provide an average capacity of $42 \mathrm{amp} / \mathrm{hr}$ of current. Even when derated at $\sim 40 \%$ for operation at $\sim 2-4^{\circ} \mathrm{C}$ ambient bottom water, these batteries provide more than enough to provide power for the sled's components during a $\sim 8$ hour tow. Normal recharge of the DSPL batteries should take no longer than $\sim 4$ hours. A bank of 4 chargers is supplied with the TowCam to facilitate simultaneous charging of all the TowCam batteries. The chargers are manufactured by MajorPower and are 24V 8 amp 'smart' chargers consisting of three stage, constant current, constant voltage and proportionally timed systems that provide fast charging and optimal timing of charge currents. Careful monitoring and recording of voltages and currents during battery charging is required to ensure proper charging and optimum bottom time, as well as long term records of battery usage so that batteries can be replaced periodically. Battery chargers are 'smart' and provide appropriate power to the battery at each stage of the charge cycle, including trickle charging at the end of the cycle. The bank of four chargers is housed in a covered plastic box, but should be positioned indoors out of the weather if possible, and should not be turned on until the cables are connected to the batteries on the Tow Cam.

\section{Digital Imaging}

The DSPL Digi-SeaCam offers a flexible, high resolution digital photography system which provides a 'drop in' solution to a variety of oceanographic imaging applications. The system used on the TowCam provides a $6000 \mathrm{~m}$ depth rated, 3.3 Mpixel, digital camera (Nikon 995 Coolpix) with a 1 GB CompactFlash card for internal image storage. The camera has a corrected dome port that generates crisp, wide angle photographs exhibiting a minimum of geometric distortion. The DSPL camera can operate in either attended or unattended modes (for time-lapse photography) and provides the capability to operate, change time lapse settings, and upload photographs without opening the pressure housing. For the TowCam, it is used in a 'simple time lapse' mode whereby the camera is programmed to have a delay that permits 
descent to the seafloor without taking photographs, thereby saving images for the seafloor traverse. The camera utilizes a DigiSnap controller board manufactured by Harbortronics (see Digisnap Manual in TowCam documentation).

The TowCam can take $\sim 1000$ digital photographs and store them internally on the 1 Gbyte CompactFlash card installed in the Nikon 995 camera inside the DSPL DigiSeacam housing. Setup for the camera and downloading procedures are described in a later section. The digital images are 2048 x 1536 color, high-resolution JPEG format files, each 800900kbytes in size. Each image is date/time stamped when acquired, but the image file names are in standard Nikon format and must be converted in order for the files to be tagged with date and time as the file name. Currently, a program installed in the Sony VAIO computer supplied with the TowCam is used for converting the files to date/time named files having the format: "yyyy-mm-dd-hh-mm-ss.jpg".

\section{DSPL DigiSeaCam Specifications \\ Camera System:}

Nikon Coolpix 995

Image sizes (user settable): 2048 X 1536 (FULL), 1600 X 1200 (UXGA), 1280 X 960

(SXGA), 1024 X 768 (XGA), 640 X 480 (VGA) 2048 X 1360 (3:2).

Optical Zoom: 4:1

Lens: Nikkor, f $2.8-5.1,10$ elements, $8-32 \mathrm{~mm}$.

Viewfinder: NTSC or PAL monitor video available on test video output connector

Storage/ File System: Design rule for Camera File systems, Digital Print-Order Format (DPOF) compliant.

Storage, Compression: JPEG-based-compliant, FINE ( 1/4), NORMAL ( 1/8), BASIC ( 1/16), HI (uncompressed: RGB - TIFF).

Storage, Media: 1 GB CompactFlash Card (Type 2)

Sensitivity: ISO 100 equivalent (selectable Auto, ISO 100, 200, 400, 800)

Shutter: $8 \mathrm{sec}$ to $1 / 2000 \mathrm{sec}$

\section{Optics}

Port: $80 \mathrm{~mm}$ diameter, hemispherical, tempered, BK-7 dome port.

Corrective optics: Multi element, pseudo-telecentric corrector, A/R coated.

Field of View:

Vertical: $46^{\circ}$

Horizontal: $74^{\circ}$

\section{SubSea Field of View}

The DSPL DigiSeaCam has been calibrated in seawater using measured poles with accurate $1 \mathrm{~m}$ markings on them. The table below provides the results of image size for three common altitudes.

Table 1. Field of view in seawater for DSPL DigiSeaCam.

\begin{tabular}{|c|c|c|c|}
\hline Altitude above Bottom & 3 meters & 5 meters & 7 meters \\
\hline $\begin{array}{l}\text { Field of View in Seawater } \\
8.03 \times 6.02\end{array}$ & \multicolumn{2}{|c|}{$3.49 \mathrm{~m} \times 2.62 \mathrm{~m}$} & \\
\hline Pixels/Meter & 586 & 338 & 255 \\
\hline
\end{tabular}




\section{Electrical}

Power requirement: $10-34 \mathrm{VDC}, 1 \mathrm{~A} \max$ (nominal .1A)

Camera Control Port: EIA, RS-232 Compliant

Camera Data (image upload) Port: USB compliant

Strobe interface: X-sync

Video output: Slow scan, 15 frames/sec, NTSC or PAL compliant

Control: External switch closures may be used to: START, or STOP time lapse, as well as snap a single photo.

\section{CTD System, Software and Data Processing}

File: Fornari SBE Setup rev4.doc

Rev 4, 25 Apr 2002. By Marshall Swartz, WHOI

\section{SETUP}

- CTD Supplied equipment

- $\mathrm{PC}$ and support equipment

- SBE Sensor Connections

- External A/D Sensor Assignments

- PC System Configuration

\section{OPERATION}

- General Operating Notes

- $\quad$ Station Sequence Table

- Deployment

- On station

- Recovery

\section{EQUIPMENT AND DATA MAINTENANCE}

- Equipment Procedures.

- Using SeaTerm with the SBE25 and SBE-CRM to test CTD.

- Files used by Seabird programs:

- Directories and Files used by SeaTerm.

- Directories and Files used by Seasave.

- Testing the SBE25 on the direct connect cable.

\section{REFERENCES}

1. SeaBird publication: SBE25 Sealogger CTD Operating Manual for s/n 0316, 29 Aug 2001.

2. SeaBird publication: SBE33 Carousel Water Sampler Deck Unit Operating and Maintenance Manual for s/n 0070, 29 Aug 2001.

3. SeaBird SEASOFT-Win32: SeaBird Data Processing and Plotting Software, software release 5.25, 09 Jan 2002.

4. WHOI internal note from Steve Liberatore: Fornari Camera Sled Control System manual, Feb 2001. 
5. Benthos/Datasonics manual: PSA-916 Altimeter for s/n 955, Nov 2001.

6. SeaPoint Systems, Inc: Seapoint Turbidity Meter User Manual for standard version, undated.

7. Flashbird documentation provided by Paul Fucile, WHOI, Mar 2002. 


\section{1. $\underline{\text { SETUP }}$}

\section{CTD Supplied equipment:}

1. SBE25 CTD s/n 2527036-0316.

2. SBE33 deckunit s/n 3327036-0070.

3. SBE CRM (Custom Release Module) Mod 90424 s/n 28158-1 or 28158-2.

4. SBE3 temperature sensor model 3F s/n 034166.

5. SBE4 conductivity sensor model $4 \mathrm{C}$ s/n 042565.

6. SBE5 pump model 5T s/n 053201-2KLV.

7. SBE29 pressure sensor model $29 \mathrm{~s} / \mathrm{n} 290455$.

8. Benthos/Datasonics altimeter model PSA-916 s/n 955.

9. SeaPoint turbidity sensor model STM s/n 1817.

10. WHOI Flash sensor model "Flashbird" s/n 001, 002 and 003.

Note: A WetLabs C-star transmissometer is not supplied but can be connected to this configuration. It is connected to one leg of a supplied WYE cable which is now "dummied off'.

Note: All CTD supplied equipment except the Altimeter s/n 955, SBE-CRM and flashbird sensors are property of the SSSG NSF Shared-use equipment pool.

\section{PC and support equipment:}

1. SBE SeaTerm Windows version 1.26.

2. SBE SeaSave Win32 Windows version 5.25.

3. Sony VAIO Laptop model PGC-GR290K with Win2000Professional, or

4. Sony VAIO Desktop with WinME.

5. Belkin USB/Serial adapters (qty 2) model F5U103 in standalone mode. 


\section{SBE Sensor Connections:}

1. SBE equipment is connected as normally defined by SBE with SBE supplied cables. See the SB25 manual for these connections.

2. Non SBE equipment is attached as follows:

1. Altimeter and turbidity meter connected to SBE WYE cable, attached to SBE25 bulkhead connector J4.

2. Flashbird sensor and transmissometer connected to modified SBE WYE cable attached to SBE25 bulkhead connector J5.

\section{External A/D Sensor assignments for SBE25 s/n 0316 for TowCam - April 2002.}

The external analog channels for the SBE25 CTD have already been defined and should not be changed.

The assignment of sensors to the bulkhead connectors and their associated byte positions in the datastream are as follows:

\begin{tabular}{|c|c|c|c|c|}
\hline & & SBE & Signal & Return \\
\hline New & Default & $\mathrm{A} / \mathrm{D}$ & Connector & Connector \\
\hline $\begin{array}{l}\text { Sensor } \\
======\end{array}$ & $\begin{array}{l}\text { Sensor } \\
=========\end{array}$ & $\begin{array}{l}\text { Chan } \\
====\end{array}$ & $\begin{array}{l}\text { and pin } \\
=======\end{array}$ & $\begin{array}{l}\text { and Pin } \\
=======\end{array}$ \\
\hline Flashbird & DO current & V0 & $\mathrm{J} 4 \operatorname{pin} 2$ & $\mathrm{~J} 4$ pin 1 \\
\hline Transmissometer & DO temp & V1 & $\mathrm{J} 4$ pin 4 & $\mathrm{~J} 4$ pin 1 \\
\hline No connect & PH sensor & $\mathrm{V} 2$ & $\mathrm{~J} 4$ pin 5 & $\mathrm{~J} 4$ pin 1 \\
\hline No connect & Spare & V3 & $\mathrm{J} 4$ pin 3 & $\mathrm{~J} 4$ pin 1 \\
\hline Altimeter & Trans Sig & V4 & $\mathrm{J} 5$ pin 2 & $\mathrm{~J} 5$ pin 3 \\
\hline Turbidity & Fluor Sig & V5 & J5 pin 4 & $\mathrm{~J} 5$ pin 5 \\
\hline
\end{tabular}

With the hardware channels for V2 and V3 unconnected, the SBE25 configuration control program in SeaTerm (the "cc" command) has been set to eliminate these two channels from the datastream, leaving only four consecutive external voltage channels, which are seen by the SeaTerm and Seasave software as V0 through V3.

Thus, the assignment of external voltage channels in SBE software to the external CTD sensor becomes:

$\begin{array}{ll}\text { V0 } & \text { Flashbird } \\ \text { V1 } & \text { Transmissometer } \\ \text { V2 } & \text { Altimeter } \\ \text { V3 } & \text { Turbidity }\end{array}$

Note: The Altimeter and turbidity sensor will not be powered up until after the unit is in salt water. 


\section{PC System Configuration:}

Either of two Windows-based personal computers have been setup for this application:

1. VAIO laptop running Win2000 professional.

2. VAIO laptop has SONY port replicator installed.

Two Belkin F5U103 USB to Serial converters are used with the chosen PC to provide two serial ports for the Seabird software to access the SBE33 deckunit.

USB Adapter Configurations:

Each USB/Serial adapter is used in "stand-alone" mode, meaning it is only plugged into the USB port on the PC and to the serial port on the SBE33 deckunit. The adapters derive their power from the PC, and do NOT use the Belkin F5U100 USB hub station for power and central USB services.

The two Belkin USB/Serial converters have already been configured by the PC. USB/Serial converter " 1 " appears to the PC as "com4" and converter " 2 " appears to the PC as "com5". This should not be changed.

USB Cables:

Two 6-foot USB "Type A/B" cables are supplied, and have been labeled as " 1 " and " 2 ". Plug USB cable " 1 " into the USB/Serial adapter " 1 ", and USB cable " 2 " into USB/Serial adapter "2".

\section{Serial Cables:}

Two 6-foot DB25M to DB9F serial cables are supplied, and have been labeled as "1" and " 2 ".

\section{Serial connections:}

Plug "1" into the DB25F socket on the back of the SBE-33 deckunit labeled "SERIAL DATA". Plug the other end (DB9F) into the USB/Serial adapter " 1 ".

Plug " 2 " into the DB25F socket on the back of the SBE-33 deckunit labeled "CAROUSEL DATA". Plug the other end (DB9F) into the USB/Serial adapter "2". 


\section{USB Connections:}

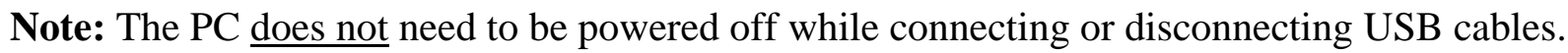

There are three USB sockets available on the back of the Sony VAIO desktop. There are three USB sockets available on the back of the Sony VAIO laptop when the Sony port replicator is used. If the Sony port replicator is not used, there are two USB sockets available.

Plug each of the two USB cable ends into any two available USB sockets on the port replicator and/or the PC. For the purposes of this application, all of either of the PC's USB sockets are identical and interchangeable.

Each of the Belkin USB/Serial adapters will automatically be recognized by the PC as being the proper serial port. 


\section{OPERATION}

\section{General Operating Notes}

On the TowCam, the SBE25 CTD serves several purposes:

1. Provides telemetry channel for real-time altimetry.

2. Senses strobe flash output and documents in the CTD datastream.

3. Provides means to trigger winch operation on the camera sled.

4. Provides standard CTD data along with optional optical parameters such as turbidity and/or transmissometer.

The SBE25 comes with a Seabird manual that documents the operation and maintenance of the hardware and software. Except for important details that may not be obvious to the user, it will not be covered in detail here.

It is expected that the user will have completely read and understood the Seabird SBE25 manual, the SBE33 manual, and the documentation provided by Steve Liberatore in the operation of the camera sled junction box (J-box) electronics.

The Operation section describes the Station Sequence in several parts. It is intended to serve as a checksheet of operations. Follow it exactly! The parts are:

- Deployment

- On station

- Recovery

\section{Batteries in the SBE CTD:}

The SBE25 can be run from internal batteries even when using the SBE33 deckunit to power it on the seacable. These are qty 9 each 1.5 volt "D" size Alkaline cells. They are used to keep up the system voltage in addition to the CTD's internal lithium cell. It is imperative to use the SBE25 slide power switch to power off the unit when not in use or these batteries will discharge and possibly cause unpredictable results.

The SBE25 manual describes how to insert these cells and monitor the battery voltage. As used on the TowCam, the SBE25 has Alkaline cells installed.

\section{REMOVING CTD BATTERIES:}

Batteries should be kept in the CTD only during the cruise, and MUST BE REMOVED when storing or shipping the CTD to avoid leakage and damage to the CTD. Anytime the CTD is to be unused for more than five days (120 hours), the batteries must be removed. 


\section{STATION SEQUENCE **FOLLOW THESE STEPS EXACTLY**}

\section{PRE- DEPLOYMENT:}

1. Start the SeaSave software.

2. Seasave will default to the previously saved configuration that should be CRM01.cfg. If in doubt, choose CRM01.cfg configuration file to bring up the display windows.

3. The five panel screen will come up as shown below:

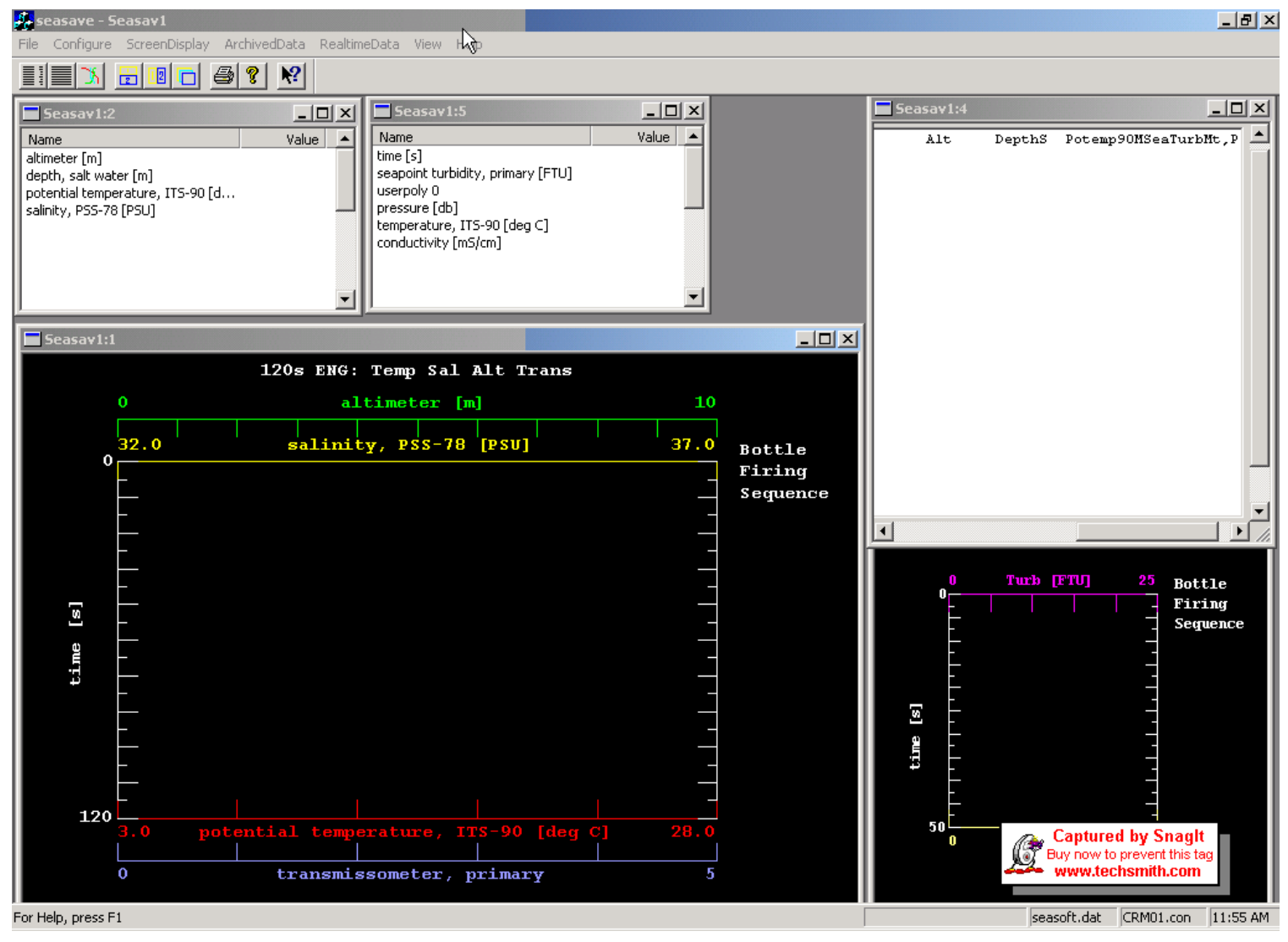

Note: The graphical window is running on the Time axis, not Depth axis, due to the nature of the Camera sled work.

4. Seasave Software window repositioning: The Seasave software has limited user configuration ability. The default windows setup with the CRM.ini initialization panel has five view panels, one of which must be scrolled within its existing window bounds to view the parameters it is displaying. This is the upper right-hand panel, which has the parameters positioned to the right off the window's edge. Manually select that window as the active window, and use the cursor to scroll the panel to the right edge of that window to display the top header line and real-time data below. 
5. All windows can be modified "on the fly" while data is being acquired without causing a data loss.

6. Choose RealTimeData on the top line, and then Start Acquisition on the drop-down menu. This will bring up a pop-up "Acquire and Display Real-Time Data Setup" window.

7. Keep the default Instrument configuration (.con) file.

8. Choose the desired output data file name in the data directory.

9. Do NOT change the port configuration options.

10. Do NOT click the Start Acquire button yet.

CAUTION: Do not shut down the SBE33 deck unit for any reason while the Winch enable shorting plug is installed, or else the winch controller may deploy multiple releases. No electronics will be damaged however, so if there is some critical need to shut down the SBE33 deckunit, this will not be catastrophic.

REMEMBER: Shorting plugs are the LAST items to be installed before deployment, and the FIRST items to be removed when working on the Sled system. Always replace shorting plugs with Non-shorting dummy plugs.

Shorting plugs have red tape on their handles with clear shrinktube over them. Non-shorting dummys have NO red tape on their handles.

WARNING: Shorting plugs should ONLY be installed into the "enable" jacks on the CD J-box. NEVER USE SHORTING PLUGS ANYWHERE ELSE!!!! 
After starting the Seaterm software in the lab follow these directions:

\begin{tabular}{|c|c|}
\hline On the Sled & In the Lab \\
\hline $\begin{array}{l}\text { INITIAL CONDITIONS: } \\
\text { 1. All shorting plugs removed from PD } \\
\text { J-box. } \\
\text { 2. Battery cables may or may not be } \\
\text { connected. } \\
\text { 3. Two 8-pin connectors from CRM to } \\
\text { CD J-box are connected. } \\
\text { 4. CD J-box connected to PD J-box. } \\
\text { 5. SBE25 CTD slide power switch } \\
\text { OFF. }\end{array}$ & $\begin{array}{l}\text { INITIAL CONDITIONS: } \\
\text { 1. SBE33 deckunit powered OFF. } \\
\text { 2. SBE Seasave program started as } \\
\text { instructed above. }\end{array}$ \\
\hline \multirow[t]{2}{*}{$\begin{array}{l}\text { 1. If not already removed, disconnect all } \\
\text { three shorting plugs on PD J-box in } \\
\text { any order. } \\
\text { 2. Connect all battery box cables to the } \\
\text { PD J-box (if they have been } \\
\text { disconnected for charging. } \\
\text { 3. Connect the Strobe, Camera and CD } \\
\text { J-box cables to the PD J-box in any } \\
\text { order. } \\
\text { 4. If needed, connect two 8-pin cables } \\
\text { from CD J-box to CRM being } \\
\text { careful to match color labels. } \\
\text { 5. Slide SBE CTD power switch to } \\
\text { "ON" position. } \\
\text { 6. Remove the fill hose or cover from } \\
\text { the SBE3 temperature probe. }\end{array}$} & \\
\hline & $\begin{array}{l}\text { 1. Turn ON the power switch on the } \\
\text { SBE33 deck unit and wait for the deck } \\
\text { unit initialization lights to finish. } \\
\text { 2.Click on the Start Acquire button on } \\
\text { the SeaSave program. }\end{array}$ \\
\hline \multirow[t]{2}{*}{$\begin{array}{l}\text { Reconnect all three shorting plugs on the } \\
\text { PD J-box in any order. Winch system is } \\
\text { now fully enabled. }\end{array}$} & \\
\hline & $\begin{array}{l}\text { The system is now ready for deployment. } \\
\text { Notify the Bridge and Winch and await } \\
\text { ok to deploy. }\end{array}$ \\
\hline
\end{tabular}

IMPORTANT- WHEN DEPLOYING THE SBE-25 ON THE TowCam!!

Remember with ANY pumped SBE CTD system such as this one, you must bring the CTD into the water to 10 meters, hold that depth for approximately 1 minute to allow air to bleed from the plumbing, and then proceed to desired depth. 


\section{IMPORTANT ITEMS ON STATION:}

Seasave Start Acquire responses:

After hitting the Start Acquire button, a pop-up window will appear indicating the program is trying to communicate with the SBE32. This should complete within about 5 seconds and this pop-up will disappear. Immediately another pop-up will appear which shows the program attempting to communicate with the CTD, and directing the user to turn on the magnetic switch on the (SBE25) CTD (which is already on). This will disappear after about 5 seconds and data acquisition will start.

If either of these windows remains on, then the $\mathrm{PC}$ is not communicating with that part of the CTD system. Check for loose USB cables, CTD slide switch off, etc.

\section{Altimeter erratic output:}

The Altimeter may have inconsistent behavior until much closer than 100 meters of the bottom. This means that there may be erratic indications on the altimeter height off bottom until the altimeter is within 30 meters or less.

If Sled must be recovered to deck but will go back in water immediately:

Suggest that the acquisition system be kept running. Do not power down deck unit or CTD, nor remove the shorting plugs.

The Camera and Strobe power systems are independent of the Winch power.

This means that the Camera and Strobe enable plugs can be on or off as needed without concern as to the power up state (battery connected, SBE33 power on, Winch enabled) of the Winch system. This is mentioned to facilitate troubleshooting.

\section{SBE25 CTD Pump delay:}

The CTD will not start the pump until the conductivity channel reads a frequency over a preset hurdle frequency. When this frequency is found, the circuit waits 45 seconds, then turns on the pump. Then 10 seconds later the power is energized for devices on bulkhead J5, which include the altimeter and turbidity sensor. The Flashbird is always on if the CTD is on. Therefore, on deck, the altimeter and turbidity sensor will not report a signal with Seasave software running, as they are getting no power. 


\section{RECOVERY SEQUENCE}

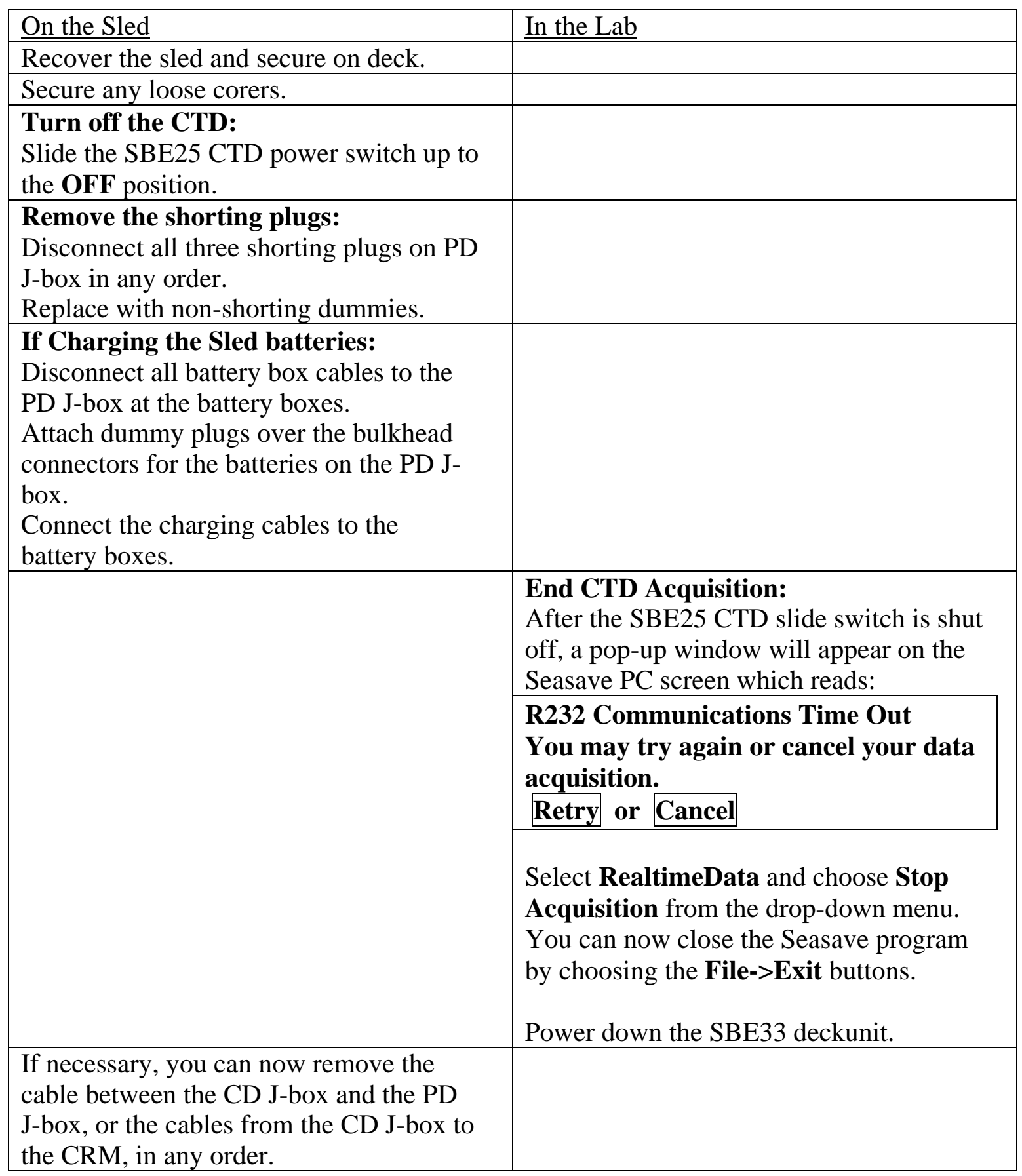

Be CERTAIN to turn off the CTD power slide switch after the cast or the "D" cell batteries inside the CTD may run down and leak, causing damage to the CTD. 


\section{EQUIPMENT AND DATA MAINTENANCE}

\section{Equipment Procedures:}

- $\quad$ SBE25 CTD should be powered off at the slide switch when not in use.

- After recovery, ALWAYS hose down entire SBE25 with fresh water.

- Refill syringe with De-ionized water and fill CTD temperature inlet after station.

\section{Using SeaTerm with the SBE25 and SBE-CRM to test the SBE25 CTD.}

The SeaTerm program is a communications program enabling users to communicate with, setup and perform memory maintenance on the SBE25 CTD.

It is used here to do system checks prior to a cruise, and to clear system memory.

Important! During setup of SeaTerm 1.26 with the SBE25 CTD and CRM hardware configuration, the SBE19 option should be selected. This is due to the modifications to the CRM. SBE25 should not be selected in SeaTerm for configuration.

Communications rate: The $\mathrm{PC}$ with the USB/serial adapter communicates with the SBE33 deckunit at 9600 baud, which is specified by the CRM.ini setup file. The SBE33 deckunit, when it starts up, sends configuration data to the SBE-CRM to define the communications rate which will be used by the CRM with the SBE25. This CRM to SBE25 rate is set by switch S1 on the "digital board". This rate is set to 600 baud, which is the default.

1. Start with SBE33 deckunit powered off, SBE25 slide switch off.

2. Start SeaTerm 1.26 program.

3. Select File, then Open Instrument Configuration.

4. Select CRM.ini.

5. To check the configuration of the communication parameters to the CTD, click on Configure, then click on SBE19... in the drop-down selection menu. This brings the pop-up window showing the present communication parameters for the CTD serial data.

6. Under the tab "COM Settings", the following should be selected (insert capture here). Then exit. Back on the main SeaTerm screen, the "status line" at the bottom will show "SBE19 ver? COM4 9600,7,1,E”. This is not an error.

7. Click on Connect button. The SeaTerm software will scan various communications rates. It may end with a popup panel saying it cannot connect. Ignore this popup if it appears by clicking $\mathbf{o k}$. 
8. Now turn on the SBE33 deckunit power switch. Hit the Enter key several times to get the $\mathbf{S}>$ prompt from the CTD.

9. Communications has now been established with the CTD. NOTE: If more than 2 minutes passes since you have connected, the CTD will time-out and you must reestablish communications by hitting the Enter key again.

10. Verify operation of the SBE25 CTD by typing DS Enter at the S> prompt. This will produce a 13 or more line response verifying battery voltage, number of analog channels and some other info. Wait until this has finished, about 5 seconds or less until another $\mathbf{S}>$ prompt appears. If it does not, hit the Enter key until it does.

11. The SBE25 has already been pre-configured using SeaTerm with the following parameters into its EEPROM, as shown by the response to the "cc" command in SeaTerm in the example captured below. This should not need to be run again, but is shown to enable a user to reconfigure the CTD if the parameters are lost in EEPROM.

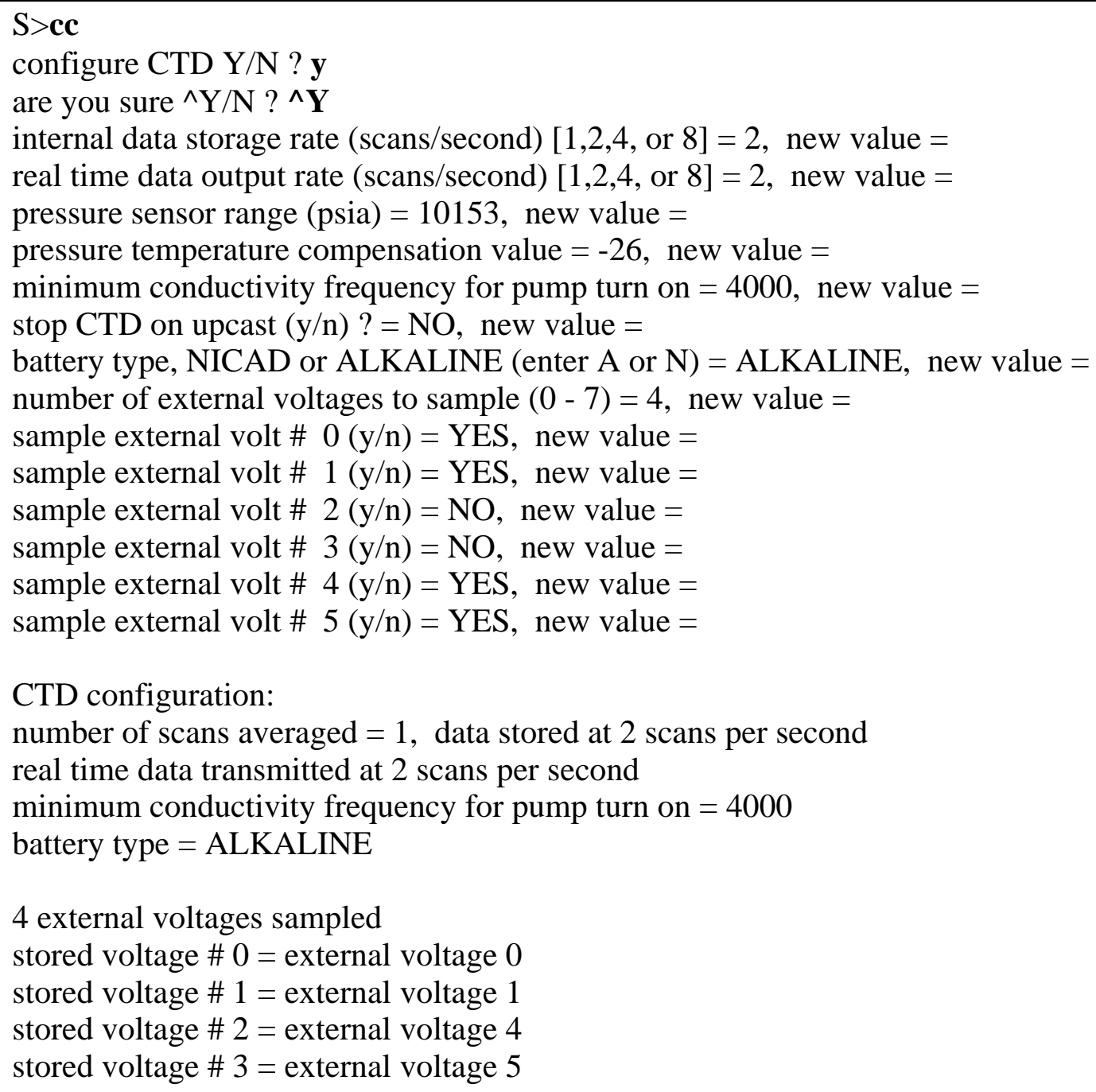


12. Refer to the SeaBird SBE25 manual for information on running Seaterm commands.

13. When done with Seaterm, at the S> prompt, type QS Enter ONLY ONCE!!! This puts the SBE25 CTD into quiescent mode to save battery energy.

14. Quit the SeaTerm program by clicking the upper $\mathbf{X}$ close window icon, or selecting File->Exit on the SeaTerm command bar. Do not press any other keys, and do not click the STOP button on the top control line. Such actions will restart the CTD. If this happens, re-enter the QS Enter command again. 
Files used by SeaBird programs:

\section{SeaTerm version 1.26:}

1. Opens, creates and modifies .ini files in $\mathrm{C}$ : Iprogram files $\backslash S B E \backslash S e a T e r m .-T h e s e$ files define the initial conditions for various predefined configurations of instruments.

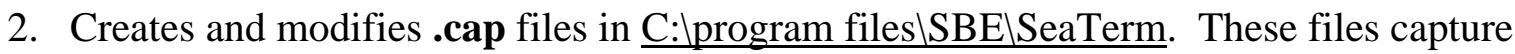
the screen session of SeaTerm. Existing .cap files will be destructively overwritten if specified, and not appended to.

Note:

Because of the special configuration of the SBE CRM with the SBE25 CTD, the SeaTerm program is required to be setup to think the CTD is an SBE19. Because of differences in response of the CTDs to prompts, the SBE25 cannot upload data to the SeaTerm program while the program is in the SBE19 mode. Therefore, the SeaTerm will NOT output a .hex or .dat file as a result of an attempted memory upload from the CTD as it normally could. This upload feature is not anticipated to be used by the camera sled and should not be an issue, but this note is provided for completeness of documentation. 


\section{Seasave (Seasave Win32) version 5.25:}

1. Opens, creates and modifies .cfg files in file:

C:Iprogram files\Sea-Bird $\backslash$ Seasave-Win32. These files define the initial conditions for various predefined instrument configurations, including:

a. naming the .con file giving calibration coefficients for attached sensors;

b. graphical layouts of the windows available in the Seasave program with .dso, .dsf, and .dss files;

c. providing definition of water sampler types and configuration and firing scheme (sequential, user-defined or table driven)

2. Opens, creates and modifies files defining Seasave display windows. These files are:

a. Fixed display files with updated fields use .dsf extensions.

b. Scrolling display files with header line use .dss extensions.

c. Graphical display files use .dso extensions.

3. Opens, creates and modifies .con files in the D:ISBElCamSled $\backslash$ Data directory containing calibration coeffients for the specified instrument configuration.

4. Creates and destructively overwrites file ConReport.txt containing a text report of the entire contents of the .con file.

5. Creates and destructively overwrites .hex or .dat files for output of the acquisition program into the $\mathrm{D}: \backslash \mathrm{SBE} \backslash \mathrm{CamSled} \backslash \mathrm{Data}$ directory. Opens existing .hex or .dat files in the $\underline{\mathrm{D}: \mathrm{SBE} \backslash \mathrm{CamSled} \backslash D \text { ata }}$ directory for viewing of previously archived data.

6. Creates and destructively overwrites .bot files for output of the bottle firings into the D: $\backslash$ SBE $\backslash$ CamSled Data directory.

\section{Backup directory for Critical Data:}

All critical setup files are backed up into the directory D:ISBElCamSled\Backup. These include predefined .ini, .cfg, .con, .dsf. .dso, .dss and sample capture files of the instrument as it was configured on April 24, 2002 aboard Atlantis. 


\section{Testing the SBE25 on the direct connect cable:}

(Assumes powering the SBE25 CTD from the SBE33 deckunit, and the SBE25 has internal batteries installed.)

1. SBE25 CTD power off at CTD slide switch. The SBE33 deckunit is NOT needed for this test and is disconnected from the SBE25 CTD.

2. Connect data cable from SBE25 to PC on COM4 USB-serial adapter.

3. Start SeaTerm.

4. Select File, Open and choose file:

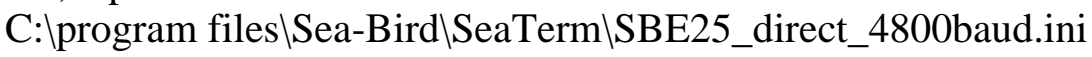

5. Select capture, define a capture file name (it can append to an existing file.)

6. Select connect.

7. Hit "ENTER" key (“<ENT>”) several times to get $\mathrm{S}>$ prompt.

8. When SBE25 starts, do tests:

9. Display status of SBE25: type DS $\langle$ ENT $>$.

10. Display quiescent SBE25 current: type $\mathrm{J}\langle\mathrm{ENT}\rangle$, wait 10 seconds for calculations, then hit enter to get back to prompt.

11. Display voltage status of SBE25: type VR $\langle$ ENT $>$. This lists system voltages. Hit $<$ ESC $>$ to end.

12. Display frequency values of SBE25: type FR $\langle\mathrm{ENT}\rangle$. This lists temperature and conductivity frequencies. Hit esc to end.

13. Go to quiescent mode: type $\mathrm{QS}<\mathrm{ENT}>$. This puts system back to sleep, turning off external sensors.

SBE-25 CTD Data Processing for TowCam Lowerings

\section{By Deborah West-Mack, WHOI. Edited by Marshall Swartz, WHOI}

Rev 1, July 17, 2002.

** DOCUMENT IN EDITING- NOT COMPLETE!

\section{Purpose of Document:}

Describe the steps necessary to process CTD data gathered by the SBE25 system during camera sled tows to usable CTD products.

\section{Intended Audience:}


The at-sea technician responsible to provide CTD data. The tech should be, and for this procedure is assumed to be familiar with:

1. basic functionality of the Tow Cam systems,

2. basic SBE-25 CTD and SBE-33 deck unit operations, and

3. startup of the SBE windows-based data acquisition system.

\section{OUTLINE \\ Introduction \\ Process Overview \\ Processing Steps \\ SBE software data processing \\ Matlab-based data processing Summary}

\section{INTRODUCTION}

The TowCam system uses a Sea-Bird SBE25 CTD underwater unit to provide basic oceanographic measurements during a traverse, as well as to telemeter data to the surface through conducting cable to the SBE33 CTD deckunit. These data include temperature, salinity, depth, altitude off bottom, camera strobe detection, and water turbidity.

Prior to each camera tow the CTD data acquisition system is started by the camera sled technician. This software is the standard SBE windows-based data acquisition system, loaded onto a laptop data acquisition PC, acquiring data from the SBE33 deckunit. The software provides real time observation of the camera sled conditions, enabling maneuvering near the bottom by monitoring altitude data. During the tow, all CTD data is being stored on the data acquisition PC for later processing, including records of corer winch deployments. After a sled tow is complete, the data is backed up and available for further analysis.

This procedure describes how to process the acquired CTD data on the PC to provide data products useful to the cruise scientists and technicians. 


\section{PROCESS OVERVIEW}

$\underline{\mathrm{ABC}}$ 's...

Acquire data during cast (not discussed - SAY WHAT FILE NAME STRUCTURE IS PREFERRED?)

Backup data after cast BACKUPON SHIP BOARD NETWORK AND BURN CD ON VAIO LAPTOP

Compute data products

With SBE software

1. Convert CTD data from hex to ascii format.

2. Run "Rosette summary" to extract CTD records during core sample events.

3. Derive salinity during core sample events

4. Compute 1-second bin average data during entire cast.

With Matlab processes

1a. Load corer (bottle) sample file

1b. Correct time to GMT and write file.

2a. Load ascii-converted CTD file

2b. Scan CTD file for flash events, rewrite file with GMT corrected time

3a. Load in 1-second bin average file

3b. Correct time to GMT

Document results

Back up results

Prepare for next cycle.

\section{STATE WHERE MATLAB PROGRAMS RESIDE ON SONY VAIO AND WHERE BACKED UP}

\section{PROCESSING STEPS}

Discuss directory structure on pc.

Discuss data compartmentalization on pc.

open Sea-Bird SBEDataProcessing-WIN32

Run/7. Data Conversion ...

Inputs:

Outputs:

setup file df_dat.psu

con file stationfilename.con

input directory

input file stationfilename.hex

output directory

name append ---

output file stationsfilename (should automatically update)

[start process]

[exit] 
Run/12. Rosette summary ... (run only if there were core samples collected) setup file df_ros.psu con file stationfilename.con input directory input file stationfilename.ros output directory name append --output file stationsfilename $\quad$ (should automatically update)

[start process] [exit]

Run/8. Derive ... setup file df_derive.psu con file stationfilename.con input directory input file stationfilename.cnv output directory name append --output file stationsfilename (should automatically update)

[start process]

[exit]

Run/4. Bin Average ...

setup file df_binavg.psu

input directory input file stationfilename.cnv output directory name append avg output file stationsfilename (should automatically update)

[start process]

[exit]

change software

close SBE Processing

open Matlab

set current directory appropriately

example processing of AT7-13_camtow5

$\%$ read in the core/bottle sampling file

$\%$ bt15 - user variable name

$\%$ read_btl - matlab function

$\%$ 'at7-13_camtow5.btl' - example bottle file name which must be in quotes

>> btl5=read_btl('at7-13_camtow5.btl'); 


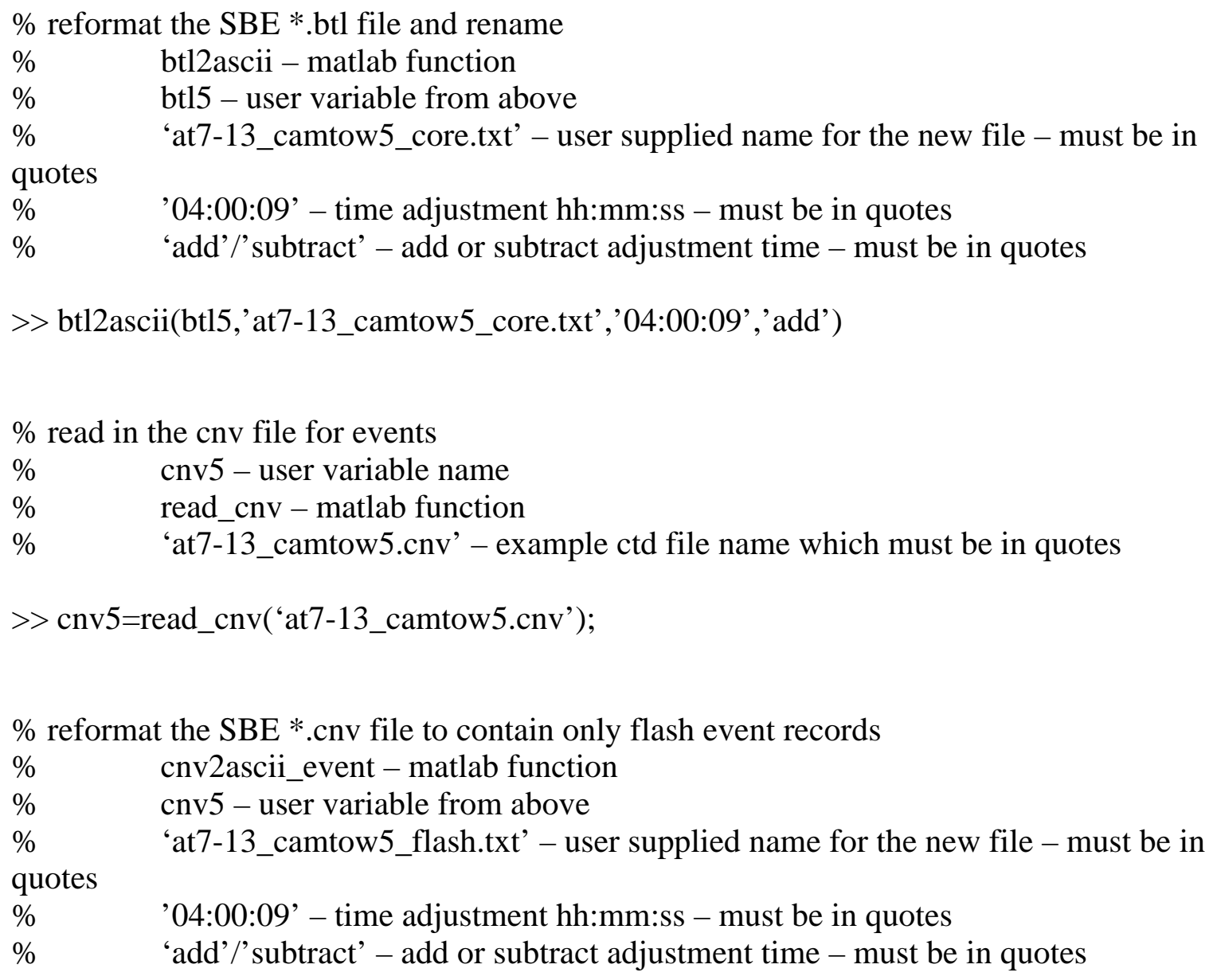




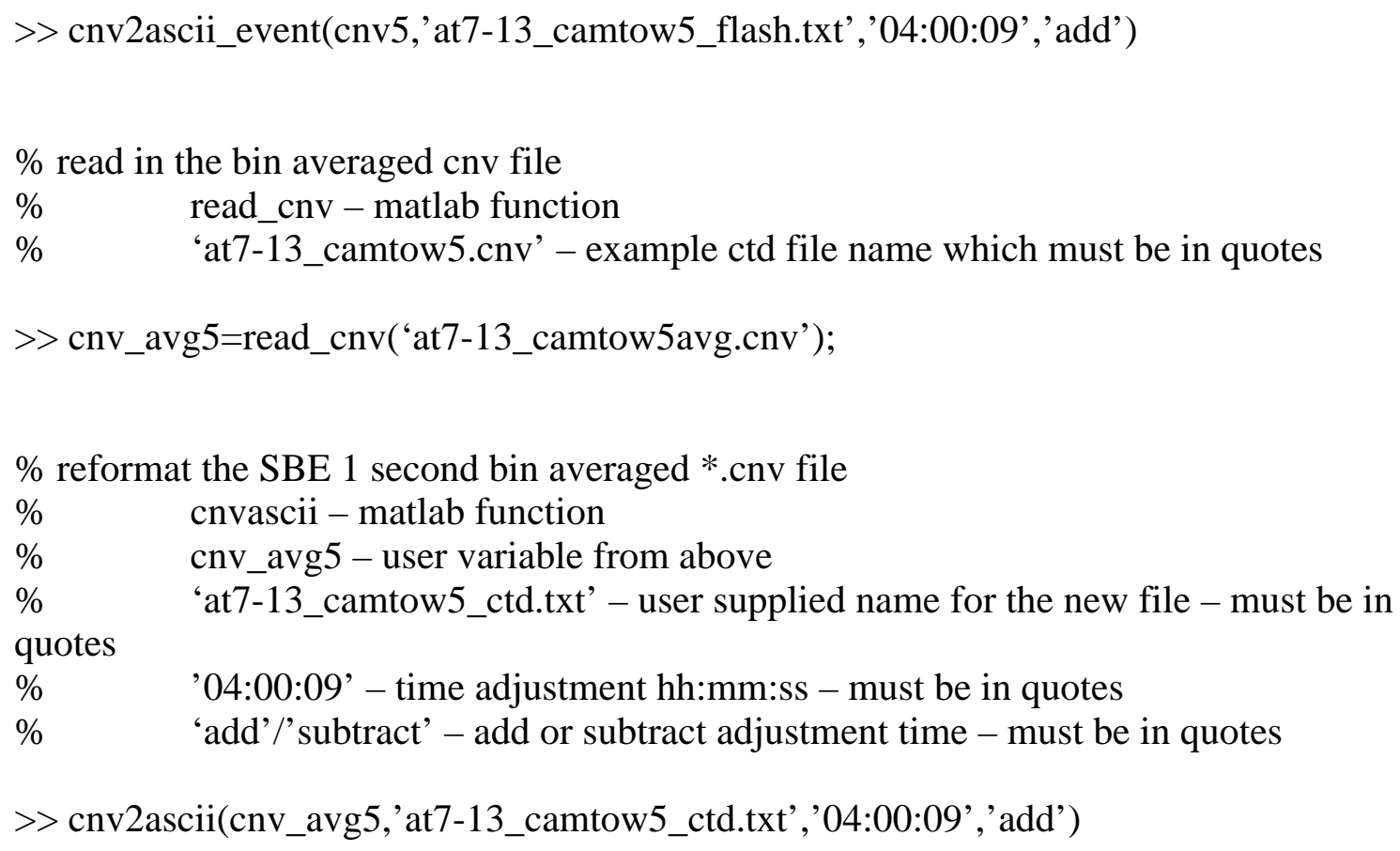

\section{SHOW EXAMPLE FILES STRUCTURE/HEADERS IN TABLE FOR EACH OF THREE} FILE TYPES

\section{Rock Coring Winches}

The Tow Cam is equipped with six (6) modular, WHOI designed electrical winches and corer assemblies capable of deploying and recovering small, stainless steel rock corers to collect basalt glass samples.

\section{Winch Motors}

Wax coring DC motor should run at $0.30 \mathrm{Amps}$ at $24 \mathrm{v}$. If there is a significatly greater current draw, then there is a problem with the motor.

\section{Rock Corer Sample Recovery/Processing Steps}

$\underline{\text { Removing Glass from the Coring Heads }}$

1) Only process one sample at a time. This will ensure that no samples get mis-labeled.

2) Remove corer ball from winch unit, placing it in plastic bag or on a paper plate, then hanging it up taking care not to contaminate it with other samples or other material from the ship's deck (Figure 1a-b).

3) Scrape all glass covered wax, using spatula/knife, into a plastic micro-waveable container. If there is lots of glass, the heat gun can be used to get the large pieces off of the ball and then the small pieces can be scraped off (Figure 2a-b). Make sure all of the basalt glass is removed from the corer ball to prevent contamination of subsequent samples. 
4) Fill the container with the glass-wax mixture with hot tap water. Place in the microwave for 1-2min (depending on quantity of wax).

5) Decant the water into the waste container, being careful not to lose any of the glass chips. DO NOT PUT WASTE WAX DOWN THE SHIP'S DRAINS.

6) Repeat steps 4-5 until all the wax is removed from the glass chips.

7) Pour alcohol on top of the glass chips (enough to cover). Swill the alcohol around the container then pour off, repeat (Figure 3)

8) Empty the glass chips onto a piece of weighing paper that is labeled with the sample number to dry, being careful not to allow mixing of the samples.

Note: The small plastic containers can be re-used by filling to the top with water then boiling in the microwave for $\sim 1 \mathrm{~min}$. Wipe out any excess with paper towel. Make sure there is no glass left in the container - if there is discard the container and use a new one.

\section{Preparing the Coring Heads}

1) Melt one of the clean tubs of wax in the microwave by placing it inside the round Tupperware container filled with water (ie. double-boiler). The wax must not be put in the microwave without an outer container of water or it will burn. A full tub of wax will take around 20 minutes to melt. Putting the new wax out in the tropical sunlight will help speed this process. Be sure to keep the cover on so the wax does not get contaminated.

2) Use a heat gun to smooth any wax remaining from the previous tow (Figure 4). It is not necessary to remove all wax from the ball - just be sure to remove any contaminated or dirty wax.

3) Remove the wax tub from the water bath. Dip the ball into the melted wax - swirl around for around 30secs, until all is coated. Leave to dry (Figure 5). The heat gun can be used on the cool setting to decrease drying time.

4) Repeat step four 2-3 times until the ball is sufficiently coated. You should still be able to see the metal edges of the coring heads (Figure 6)

5) Hang the corer balls and leave to dry for $\sim 30$ minutes to fully dry before reloading the winch unit.

\section{TowCam Operations Guidelines \\ General Comments}

The TowCam operates in the corrosive environment of the open ocean. Salt water will corrode housings and seals quickly. Rise off the system often with fresh water, hosing carefully around all component pressure housings. This must be done immediately after a tow, prior to downloading images, and should be done once every few days if the system is on deck 
to rise off the salt spray. All housings should be checked and seals/O-rings cleaned and greased prior to the expedition. Before departing the dock, do a deck test of the system. An inwater test is preferred to provide information about connector and component water-tight integrity. A thorough visual check of all systems and the cables running to each sensor is required before and after each lowering. Check for chafing and wires that were pulled too tight, and loose connectors- wires do vibrated and flap during a tow so there needs to be some flexibility (i.e. slack) in the lines. All hose-clamps that hold on the top and side protective gratings should be checked to be sure they are not broken or chafed, if they are replace them.

Careful planning should be done in determining the best towing directions and paths over the seafloor. Where possible it is preferable to tow into the wind and weather. Tows should be doe parallel to the topography or oblique to the trend of bathymetric contours where possible to avoid going directly up steep escarpments and damaging the system. Detailed discussions with the Bridge, Bosun and deck crew should take place to go over launch and recovery procedures. The system must be restrained on all four corners when being deployed to avoid excessive pendulum motion. Do several tests of the system prior to deployment (as described below) to ensure that the camera is properly set and the CTD is on and recording.

A delay function in the camera allows for a 'sleep' mode during the lowering of the TowCam to the seafloor. One should calculate conservatively the amount of time required to deploy the camera and lower it to the bottom in order to correctly determine the wait time from when the system is turned on, on deck, to when it commences taking bottom photographs (See Table 1 and 2).

\begin{tabular}{|c|c|}
\hline Bottom Depth & 1-Way Lowering Time at $\sim 40 \mathrm{~m} / \mathrm{min}$. \\
\hline $1000 \mathrm{~m}$ & $=1500 \mathrm{sec}$. \\
\hline $2000 \mathrm{~m}$ & $=3000 \mathrm{sec}$. \\
\hline $2500 \mathrm{~m}$ & $=3780 \mathrm{sec}$. \\
\hline $3000 \mathrm{~m}$ & $=4500 \mathrm{sec}$. \\
\hline $4000 \mathrm{~m}$ & $=6000 \mathrm{sec}$. \\
\hline $5000 \mathrm{~m}$ & $=7560 \mathrm{sec}$ \\
\hline $6000 \mathrm{~m}$ & $=9000 \mathrm{sec}$. \\
\hline
\end{tabular}

Table 1. Tow Cam lowering times at 40 meters per minute

\begin{tabular}{|c|c|}
\hline Tow Speed(knots) & TowCam Travel (m/min) \\
\hline $\begin{array}{l}0.25 \\
0.50 \\
1.0\end{array}$ & $\begin{array}{l}7.7 \mathrm{~m} / \mathrm{min} \\
15.4 \mathrm{~m} / \mathrm{min} \\
30.5 \mathrm{~m} / \mathrm{min}\end{array}$ \\
\hline
\end{tabular}

Table 2. Conversion of tow speed in knots to meters per minute.

Based on experience, the camera should be lowered while the ship is in Dynamic Positioning (DP) and traveling at $\sim 1 / 4$ knot. This means that the deployment position must be carefully picked so that the Tow Cam reaches the bottom at the approximate start point of the desired traverse. Lowering the TowCam while towing it provides sufficient drag to keep the system from heaving excessively and unloading the wire while lowering. After the TowCam is in the water and the winch read out is zeroed, the package should be lowered to $\sim 10 \mathrm{~m}$ depth and held for 2-3 minutes. This permits the CTD pump to purge any air in its system. 
The package can continue to be lowered at $\sim 30 \mathrm{~m} / \mathrm{min}$ until $\sim 300 \mathrm{~m}$ of wire is out. Thereafter, if the weight on wire is fairly steady, the lowering speed can gradually be increased to 40-45 $\mathrm{m} / \mathrm{min}$. When approaching the bottom, the system should be gradually lowered to the optimum altitude of 5-7 $\mathrm{m}$ above the seafloor. Care should be taken to factor in the heave of the ship on the mean altitude during the tow.

\section{Towed Camera SystemDSPL SeaBattery Charging Protocol}

After a tow, and when the sled comes to the surface, relieve the pressure from each battery by unscrewing the small brass cap on the bladder and venting them to the atmosphere. Battery charging is a key part of maintenance of the system and will ensure that sufficient power is available for a full tow. Follow the charging instructions carefully and remember to log all charge data and save the data sheets in the notebook supplied with the system and return to WHOI on completion of the cruise. The reading for the 24V DSPL batteries should not be less than $23 \mathrm{VDC}$ for each $24 \mathrm{~V}$ battery, if so, the battery needs to be replaced as it is likely damaged. Do not open the DSPL batteries, spare DSPL batteries are provided with the TowCam system. Check oil through diaphragms to be sure you don't see any cloudy, or whitish deposits, if so it may be that the battery must be changed out. NEVER LEAVE MALE CONNECTORS UNPROTECTED AND NEVER LEAVE THEM PLUGGED INTO LIVE BATTERIES OR CHARGERS. charger.

A bank of four small chargers are supplied, each battery gets charged by its own

1. Measure voltage prior to charging and note on log sheet.

2. When on deck, batteries should be vented to prevent gas buildup, the caps should be screwed on loosely - this is sufficient to vent them

3. Batteries should be vented during charging.

4. Plug each charger into a DSPL SeaBattery.

5. Plug charger into outlet and turn on. The small LED light on each charger should turn on and be red when charging, changing to green when the charge is completed.

6. Charging should take 4-5 hrs. If you see a few bubbles coming up from the cells indicating degassing that is normal. If you see excessive degassing stop charging immediately.

\section{DSPL SeaBattery Charging Procedure}

1) Keep accurate records of battery voltages and charge cycles

2) Vent batteries, place small paper cups over the tubes.

3) Make DC connections, by plugging batteries into each charger. This is done with the batteries chargers unplugged to prevent arcing at the connector.

4) Plug in AC side of the chargers.

5) Start charging by activating the switch on the power supply, monitor the LED's briefly.

6) Batteries will recharge in 2-4 hours.

7) Shut off AC power to chargers

8) Disconnect AC side of batteries first, then remove the DC connectors (sled connectors)

9) Let batteries stand for one hour before installing vent caps.

Note: Lead acid batteries generate hydrogen, and oxygen during recharging. 


\section{Preparing for a Camera Tow using the TDCS}

Forms are provided to serve as checklists for pre/post tow tasks and to record system performance, tow location, date, etc. Fill out the forms for each camera tow and put them in the binder supplied. Figures 3 and 4 of this manual are the pre/post tow checklist forms.

Be sure to modify the pre- and post- launch forms to fit your cruise requirements. Copies of these forms should be returned to WHOI (to the attention of D. Fornari) for archiving.

\section{Launching the TDCS}

Launching should be directed by the ship's Bosun. Always wear a hard hat and a life vest when launching/recovering the TDCS. The system should not be launched in very rough weather or when it is apparent that the forecast indicates bad weather is coming. The TDCS is a large package with lots of momentum, several safety and restraining lines should be rigged for deployment and recovery per instructions from the ship's Bosun. On launch and recovery the sled should be restrained from both inboard and outboard directions (crossing lines) so that it does not swing or hit the rail of the ship. Remember to plug the shorted (RED) connector into the power junction box to start the strobe, and the other two power connectors for the DSC and the pinger/strobe monitor/temp. sensor, prior to launching the TDCS, and verifying that the system takes the required $\sim 5$ photographs after power-up.

\section{Towing the TDCS}

The primary indicator of TowCam altitude above the bottom is the CTD altimeter. The readout of the altimeter is available on the Sony VAIO laptop computer that controls the CTD acquisition. If the altimeter stops working the $12 \mathrm{kHz}$ pinger trace provides a backup capability to determine analog altitude above the bottom. Be sure to continuously monitor the pinger trace and verify the pulse length so that you correlate the pinger altitude with the CTD altitude. IF YOU DO NOT SEE SEPARATION BETWEEN THE PINGER\&BOTTOM TRACES PULL UP IMMEDIATELY AT 10 M/MIN WHILE WATCHING THE TENSIOMETER. PULL UP UNTIL YOU SEE SEPARATION AND THEN GRADUALLY LOWER TO 7M SEPARATION. USING MULTIBEAM DATA FOR THE AREA OF THE TRAVERSE, KEEP TRACK OF THE TOPOGRAPHY AHEAD OF THE SHIP/TowCam SO YOU KNOW WHEN YOU SHOULD BE PULLING UP OR EXPECTING SLOPE CHANGES.

Towing the sled is a bit of an art but your watch-standers will get used to it soon. The danger comes when you are towing over rough bottom. If the camera gets on the bottom an inexperienced operator can do damage especially if the camera gets hung up. Watch standers must be instructed on proper communication with the bridge and must be checked-out on winch and camera towing operations prior to being left in charge while the camera is being towed. If there is an emergency (like being caught on an outcrop) the bridge needs good clear instructions and a quick description of what the problem is.

When you are lowering the sled keep a close watch on the amount of wire out and give the winch watch clear instructions on when to stop. You will be able to see the bottom come up on the acoustic recorder. Count the wrap-a-rounds to keep track acoustically how far you are from the bottom. If in doubt set the acoustic recorder to a slow sweep and keep the whole picture on the chart. When you are within $\sim 30 \mathrm{~m}$ of the seafloor, the digital altimeter on the CTD will start reading consistently. As noted above, note the separation on the pinger trace and how that looks when compared to the real-time digital altitude data from the CTD. 
Recovering the TDCS

Recovery should be directed by the ship's Bosun or Shipboard Resident Technician. Remember to use restraining lines on both the inboard and outboard sides of the TowCam to keep it from swinging. Always wear a hard hat, work-vest, and closed-toed shoes when launching/recovering the TowCam. 
Table XX.

\begin{tabular}{llc} 
Rep. Rate & Tow Speed & Approximate Seafloor Coverage* \\
\hline $15 \mathrm{sec}$ & $0.25 \mathrm{kts}$ & $170 \%$ \\
$15 \mathrm{sec}$ & $0.50 \mathrm{kts}$ & $77 \%$ \\
$15 \mathrm{sec}$ & $1.0 \mathrm{kts}$. & $40 \%$ \\
& & \\
$30 \mathrm{sec}$ & $0.25 \mathrm{kts}$ & $78 \%$ \\
$30 \mathrm{sec}$ & $0.50 \mathrm{kts}$ & $39 \%$ \\
$30 \mathrm{sec}$ & $1.0 \mathrm{kts}$. & $20 \%$ \\
& & \\
$60 \mathrm{sec}$ & $0.25 \mathrm{kts}$ & $39 \%$ \\
$60 \mathrm{sec}$ & $0.50 \mathrm{kts}$ & $20 \%$ \\
$60 \mathrm{sec}$ & $1.0 \mathrm{kts}$. & $10 \%$
\end{tabular}


DSPL DigiSeaCam, DigiSnap Controls and Downloading Information 
WHOI TowCam \& Multi-Rock Coring System Manual Version 1.0

2/26/03

Steps for Downloading Images After a Tow 


\section{WHOI Towed Digital Camera System Log}

Cruise ID:

Location:

Chief Scientist:

Date of Lowering

Start/End Information (all times GMT):

Off Deck

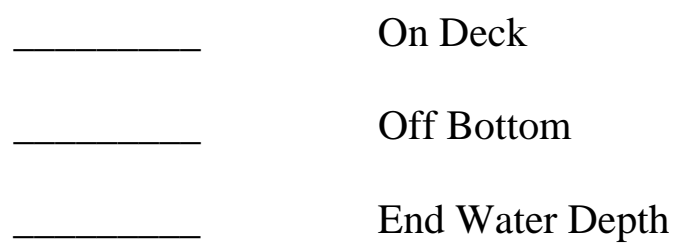

Start Water Depth

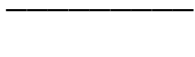

Settings:

DSPL DigiSeacam Photo Rate sec

\section{Start Camera Time}

Last Deck Picture time

Wait Time

First Bottom Picture Time

Remarks: 
Tow ID:___ Cruise: Pre-Tow Checklist

Time/Date (GMT):

Camera Tech:

\section{CHECK}

PROCEDURE

1. Batteries charged, voltages of each battery noted in Operations Log.

2. All connectors checked.

3. Battery boxes and junction box are filled with oil, bladders are intact, small band clamps on fittings are tight and hoses are not crimped or cut.

4. All shackles and safety wires checked.

5. Inspect welds at lifting tabs for cracks.

6. Swivel rotates freely and shackles and safety wires on it are OK

7. Trawl wire termination in good shape.

8. Time on Lunchbox computer synched with GPS navigation clock.

9. Previous pictures on hard drive on Digital Camera CCU have been erased.

10. Digital Camera CCU loaded with script and script has been logged in the Operations Log and in the Science Log.

11. Digital Camera CCU Deck Cable DUMMY PLUG re-installed and O-ring checked.

12. IF USED- $35 \mathrm{~mm}$ film loaded in the Benthos 377 camera and time/date in data chamber has been synched with GPS navigation clock, lens cover taken off the $35 \mathrm{~mm}$ housing.

13. Loose wires have been tie-wrapped down.

14. Battery and junction box oil drain and fill lines have pressure fittings on them and have been tie-wrapped and taped to the inside of the frame.

15. Polypro recovery loops are taped upright to facilitate grappling for sled on recovery.

16. Connect the trawl wire to the swivel and put in cotter pin or safety wire.

17. Tag lines are rigged to provide inboard/outboard restraint during launch.

18. Ship is in position and science watch standers are ready to log data and fly the sled.

19. Plug in power to sled components in this order:

Pinger power (plugs into J-Box

Strobe Power (shorted (RED) connector on battery junction box)

DSC power (plugs into J-Box)

Test for 5 strobe flashes and wait for 1 full repetition cycle (i.e. $15 \mathrm{sec}, 20 \mathrm{sec}$, etc. whichever is chosen) to ensure that camera is in wait mode.

20. The camera sled is now ready for deployment.

21. Follow directions of Bosun and deploy camera sled. 
Tow ID:__ Cruise: Post-Tow Checklist

Time/Date (GMT):

Camera Tech:

CHECK

PROCEDURE

22. Disconnect shorted (RED) plug on battery junction box and replace with Blue (unshorted) plug.

23. Disconnect DSC power from J-Box, spray w/silicon and insert dummy plug

24. Disconnect Pinger power from J-Box spray w/silicon and insert dummy plug

25. Wash down J-box and batteries, sled components and frame with fresh water

26. Secure sled to deck using chain.

27. Rig tarp to cover sled from sunlight

28. Rig vent bucket and vent batteries, check plastic tubing lines and fittings and connections to battery boxes to make sure there are no leaks

29. Check integrity of shackles, cotter pins, tie-wraps and bridle attachment points on frame, check also trawl wire termination and swivel.

30. Connect Deck Cable and start downloading images

31. Note batteries voltages of each battery and log in charging log sheets.

32. Install 6 volt battery charging bridles and start charging batteries and checking them for excessive venting, especially the DSPL batteries.

33. Complete charging and fill out log sheets

34. Install compensating oil fill lines and fill batteries.

35. Continue to download images and burn data CDs

36. Erase images from DSC hard drive in preparation for next lowering, only after you are sure that you have saved all data from the tow. 


\section{Benthos 383 Deep Sea Strobe}

The strobe used on the TowCam is a Benthos 383 HP high energy light source modified to provide an output of 600 watts into two remote flash heads using Photogenic SFT-291 xenon flashtubes. These flashtubes may be obtained from Zeff Photo Supply (888-465-7290) for \$160 each and should last for up to 4000 flashes. The $383 \mathrm{HP}$ strobe electronics differ from other 383 models by having more capacitance for energy storage and using a lower voltage (700 Volts). If it is neccessary to replace the C-383-6 flash board, care must be taken to ensure that the high voltage has been lowered from the normal +/-400 VDC to +/-350 VDC or the 360 volt-rated capacitors will be damaged. Recycle time for this configuration is about 10 seconds with starting current running as high as 9 Amps.

\section{Connectors and Cables}

The input connector on the strobe is a Seacon XSG-4-BCL and is connected to the junction box with a 10 feet long cable having a Seacon RMG-4-FS connector on the strobe end and a Seacon VMG-4-FS connector on the junction box end wired pin to pin. The "STROBE" connector on the junction box which mates with this cable is a Seacon VSG-4-BCL. The signal pin-out for the four conductors is: Pin $1=\mathrm{COMMON}$

$$
\begin{aligned}
& \text { Pin } 2=+24 \text { VDC } \\
& \text { Pin } 3=\text { ENABLE (tie to }+24 \text { to enable) } \\
& \text { Pin } 4=\text { SYNC (short to common to flash) }
\end{aligned}
$$

A special cable harness is used to connect the two remote flash heads to the strobe housing. It consists of one 8 feet long Seacon VMG-4-FS pigtail and two 8 feet long Seacon RMG-4-FS pigtails molded together in a 4-way "Ysplice" connected pin to pin. The signal pin-out for the four conductors

is: Pin $1=$ TRIGGER LO

Pin $2=\mathrm{HV}+$

Pin $3=\mathrm{HV}-$

Pin 4 = TRIGGER HI

The Seacon cables and connectors can be obtained from Seacon/Phoenix, Inc. (401-596-6658).

\section{Strobe Operation}

The flash chassis consists of a capacitor bank, high voltage power supply, and a flash control board (C-383-6). The flash control board does two things, it charges the banks of capacitors and triggers the flash heads.

\section{Charging the Capacitors}

When 24 VDC is applied to the "P" terminal (enable), C15 is charged to 24 VDC through diode D13 and R29 biasing the amplifier Q2 and Q3 on via $\mathrm{R} 22$. When on, this amplifier provides a ground path to one side of the relay coil L2 and since the other side of the coil is connected to 24 VDC via the jumper to the "B" terminal, D4 and D5, the relay will close providing 24 VDC to the high voltage power supplies PS1 and PS2. The 
capacitor pairs $\mathrm{C} 17+\mathrm{C} 18$, and $\mathrm{C} 20+\mathrm{C} 21$ in series, then begin to charge through isolating diodes D7-D10 to 700 VDC. The junction of these capacitor pairs is connected to ground providing +350 and -350 VDC with respect to common. The neon light A230, connected between -350 and ground via $\mathrm{D} 12$, has a voltage across it proportional to the voltage on capacitors $\mathrm{C} 20+\mathrm{C} 21$ due to the voltage divider formed by $\mathrm{R} 28$ and $\mathrm{R} 26 / \mathrm{R} 27$. As the capacitors charge to $700 \mathrm{VDC}$, the voltage across A230 reaches the turn-on point (about 65 VDC adjusted by R27), and the neon light conducts pulling the base of Q3 to ground (it can't go negative due to D12) to turn off the Q2/Q3 amplifier and the power supplies. As long as the neon light is on, the power supplies remain off. The capacitors will be recharged to 700 VDC if the voltage across the neon light sags to about 55 VDC or the flash is fired.

\section{Triggering the Flash Heads}

When high voltage (650-700 VDC) is available, C19 is charged to about 270 VDC through the voltage divider formed by R24 and R25. If the " $\mathrm{S}$ " terminal (sync line) is then grounded, the base of Q4 (normally held high via R18 and D11) is pulled low via D8, R17, and D11. This turns off Q4 and allows C16 to charge through R20 and trigger the SCR Q5. The flash will fire when C19 discharges through the trigger transformer T1 via the SCR producing a high voltage spike to the flashtube trigger winding. Note that the flashtube always has high voltage applied to it when the strobe is "on".

\section{Strobe Maintenance}

The unit should be washed with fresh water after each deployment and the O-rings and seals serviced per the maintenance section of the Benthos Strobe Manual.

\section{O-rings}

1. \#240 low pressure seal on endcap

2. \#243 high pressur seal on endcap

3. \#228 seal on endplate

4. \#225 seal on flash

5. \#2-213 seal on Seacon connectors 


\section{Flashbird Strobe Light Detector \\ Paul Fucile - WHOI March 14, 2002}

This circuit provides a 5 volt pulse for 3.8 seconds when it detects a strobe light flash. It connects to a SBE 25 or 911 and conforms to existing sensor cabling. The OPT101 hybrid Photodiode/amplifier detects the light and generates a pulse for the duration of the

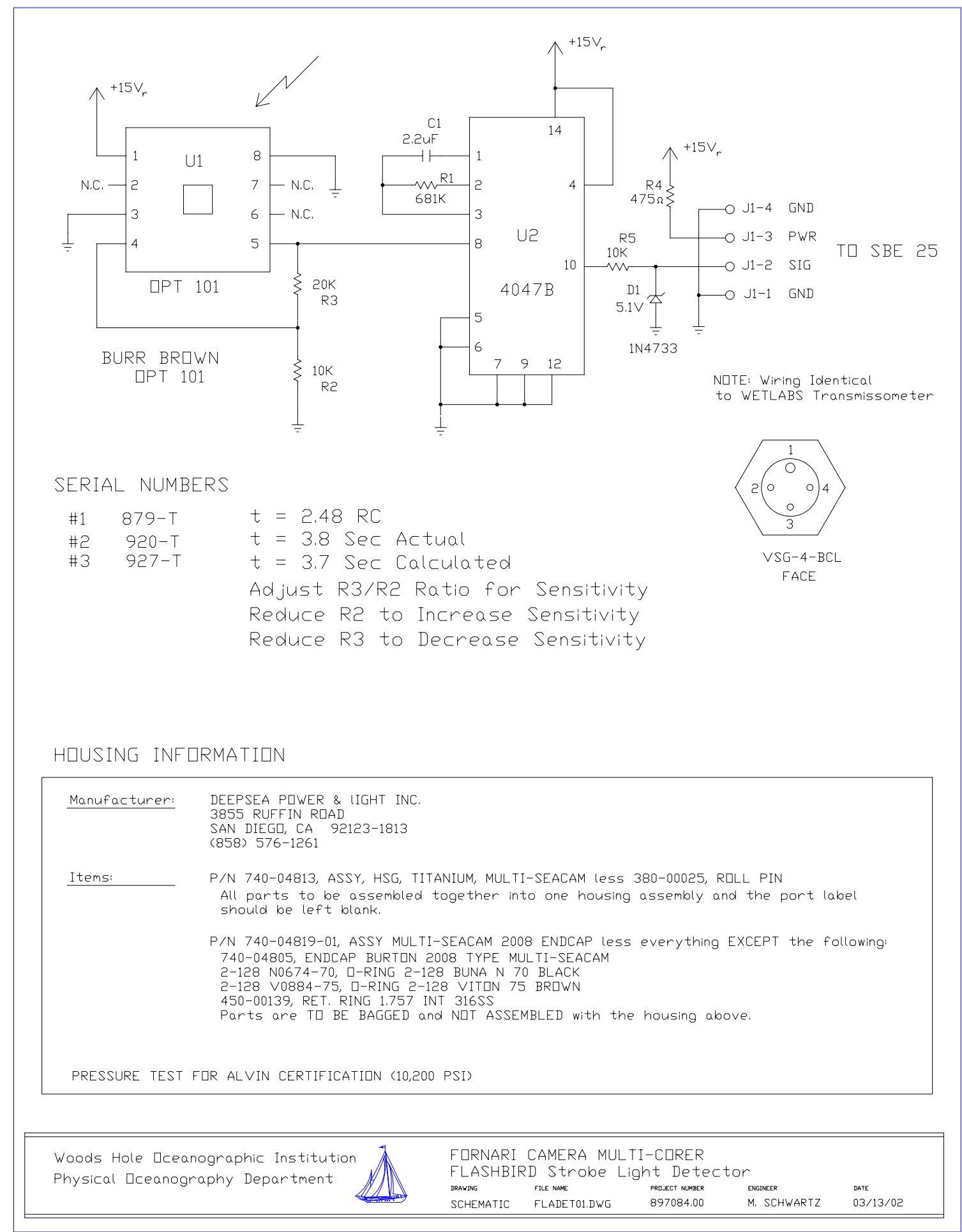


strobe period. The 4047B operates as a positive edge trigger monostable multivibrator set for a 3.8 Second pulse. The output is clamped to $5.1 \mathrm{~V}$ by D1. The pulse time is adjusted changing $\mathrm{R} 1$ and $\mathrm{C} 1$. R1 should be no greater than $1 \mathrm{Meg} \mathrm{ohm}$. $\mathrm{C} 1$ should be no greater than $2.2 \mathrm{uF}$. The optical sensitivity is adjusted by changing the ratio of R3/R2.

Depending on placement, the detector window is normally aimed at the strobe. The device can operate in daylight without damaging the sensor.

\section{Specifications:}

Operating depth: 6,000 meters. Operating temperature range: $-5 \mathrm{C}$ to $+40 \mathrm{C}$.

Power requirements: Power to the unit is supplied by the SBE CTD at +15VDC and consumes no more than 50mA.

Output signal: The Flashbird produces a one-shot positive square wave of $+5 \mathrm{Vdc}$ (referenced to power supply ground) when a flash is detected. The Vout max is not more than $+5.2 \mathrm{Vdc}$, and not less than $+4.6 \mathrm{Vdc}$. The square wave output has a rise time and fall time of less than 100 microseconds to Vout max, and a period of 3.8 seconds, +/- 0.2 seconds. The Flashbird will detect another flash not less than 0.5 seconds following the completion of the square wave output of a preceding flash. The output of the Flashbird's final amplifier has a $10 \mathrm{~K}$ ohm resistor in series to the output pin to limit output current and is clamped by a $5.1 \mathrm{~V}$ zener diode. The analog output "return" of the Flashbird is electrically in parallel to the power supply ground pin.

Output bulkhead connector: The unit uses an Impulse or Seacon VSG-4-BCL bulkhead connector. It is wired pin-for-pin compatibility to a Wetlabs transmissometer.

The pinout is:

pin 1: Common ground.

pin 2: Analog output.

pin 3: +7 to $+15 \mathrm{Vdc}$ power input.

pin 4: Analog return, parallel with common ground.

There are no exposed metallic components of the case of this instrument to common ground. 